\title{
An Artificial Neural Network Model to Forecast Exchange Rates
}

\author{
Vincenzo Pacelli $^{1 *}$, Vitoantonio Bevilacqua ${ }^{2}$, Michele Azzollini ${ }^{3}$ \\ ${ }^{1}$ Faculty of Economics, University of Foggia, Foggia, Italy; ${ }^{2} 1$ st Faculty of Engineering-Electrical and Electronic Engineering De- \\ partment, Polytechnic of Bari, Bari, Italy; ${ }^{3}$ BancApulia S.p.A., San Severo, Italy. \\ Email: v.pacelli@unifg.it
}

Received July $10^{\text {th }}, 2010$; revised October $1^{\text {st }}, 2010$; accepted December $1^{\text {st }}, 2010$.

\begin{abstract}
For the purposes of this research, the optimal MLP neural network topology has been designed and tested by means the specific genetic algorithm multi-objective Pareto-Based. The objective of the research is to predict the trend of the exchange rate Euro/USD up to three days ahead of last data available. The variable of output of the ANN designed is then the daily exchange rate Euro/Dollar and the frequency of data collection of variables of input and the output is daily. By the analysis of the data it is possible to conclude that the ANN model developed can largely predict the trend to three days of exchange rate Euro/USD.
\end{abstract}

Keywords: Exchange Rates, Forecasting, Artificial Neural Networks, Financial Markets

\section{Introduction}

The recent international economic crisis has highlighted the need for banks to implement effective systems for estimating risks of market. In particular, the international activity of the largest banks and the increasing volatility of exchange rates emphasize the importance of exchange rate risk, whose active management by the banks require the use of effective forecasting models.

The study of the topic of forecasting in financial markets is based on the research hypotheses that:

$\left(h_{1}\right)$ the process of pricing in financial markets is not random;

$\left(h_{2}\right)$ the degree of information efficiency at Fama of the financial markets is not strong or semi-strong.

If the two research hypotheses proposed were not considered valid, it would be highly redundant and useless to study the issue of forecasting in financial markets.

If the first hypothesis $\left(h_{1}\right)$ was invalid, in fact, it would assume that the processes of pricing in financial markets are governed by the random walk model, whereby the price dynamics are determined by the interaction of an indefinite variety of interacting causes not modelling and among them not ordered by relevance. In other words,

\footnotetext{
\#Although the research has been conducted jointly by the three authors, paragraphs 1, 2 and 7 can be attributed to Vincenzo Pacelli, paragraph 5 is due to Vitoantonio Bevilacqua, while paragraphs 3, 4 and 6 are a collaborative effort of the three authors.
}

we assume that the processes of pricing in financial markets are governed by the noise. This would make it useless to study models of forecasting because the case is not predictable.

If the second hypothesis $\left(h_{2}\right)$ was invalid, however, it would assume that all relevant information are instantly incorporated in the pricing of financial products, making essentially unnecessary and economically inconvenient any efforts to develop models to predict the future based on present information.

This research aims to analyze the ability of mathematical models of nonlinear nature, such as artificial neural networks, to highlight non-random and therefore predictable behaviour in a highly liquid market and therefore characterized by high efficiency, such as the exchange rate Euro/US dollar. To this end, it was developed and empirically tested a non-linear model for forecasting exchange rates.

Economic theory has not yet provided econometric models to produce efficient forecasts of exchange rates, although many studies have been devoted to the estimation of equilibrium of exchange rates, including:

1) Cassel [1], Samuelson [2], Frankel [3], MacDonald [4], Alba and Papell [5], Alba and Park [6], Coacley, Flood, Fuertes and Taylor [7], Kim B.H., Kim H.K. and Oh [8], Taylor [9], Grossmann, Simpson and Brown [10] on the theory of Purchasing Power Parity (PPP); 
2) Mundell [11], Dornbusch [12,13], Frenkel [14], Frenkel and Mussa [15], Rogoff [16] on the monetary approach;

3) Branson [17], Branson and Henderson [18], Allen and Kenen [19], Cifarelli and Paladino [20] on the approach of financial assets or balance of the portfolio.

Despite significant advances in econometric theory on the estimation of exchange rates, empirical results emerging from many studies, among others, Frankel [21] and Froot and Rogoff [22] to refute the theory of purchasing power parity; Frankel [23] against the monetary model, Branson, Halttunen and Masson [24] and Frenkel [25] to refute the theory of financial assets do not provide special support to the theories mentioned, except in the long term.

In particular, Meese and Rogoff [26] found that none of the forecasting models of the exchange rate established by economic theory has a better ability to forecast, over a period lower than 12 months, rather than the forward rate models or random walk, emphasizing the paradox that the variations of exchange rates are completely random. In the wake of the study of Meese and Rogoff [26], some authors, including Hsieh [27], Vassilicos, Demos, Tata [28], Leroy, Nottola [29], Refenes, Azema Barac, Chen, Karoussos [30], Nabney, Dunis, Dallaway, Leong, Redshaw [31,32], Brooks [33], Tenti [34], Dersch, Flower, Pickard [35], Lawrence, Giles, Tsoi [36], Rauscher [37], El Shazly MR, El Shazly HE [38], Gabbi [39], Gencay [40], Soofi, Cao [41], Sarno [42], Alvarez and Alvarez-Diaz [43-45] Alvarez-Diaz [46], Reitz and Taylor [47], Anastakis and Mort [48], Majhi, Panda and Sahoo [49], Bereau, Lopez and Villavicencio [50], Norman [51], Bildirici, Alp and Ersen [52], have studied the predictability of the dynamics of exchange rates of non-linear models such as neural networks, genetic algorithms, expert systems or fuzzy models, leading however to conflicting results.

It is unnecessary to underline that the theme of forecasting in financial markets is not confined to the specific case of foreign exchange markets, but it is extended to all financial assets. This is because the mechanisms that determine and influence the pricing in financial markets are still largely unknown, although many studies have been devoted over the years at this issue as early as by Keynes in chapter 12 of Book IV of his The General Theory of Employment, Interest and Money in March of 1936 [53]. After Keynes, some authors (Meese and Rogoff [26]; Schiller [54]; Soros [55], Obstfeld and Rogoff, [56]; Rogoff [57]) have highlighted the inability of economic theory to unravel the mechanisms that determine price movements in financial markets, highlighting the inadequacy for the purpose of both models of fundamental analysis and technical one.
In general, the prediction of financial time series requires the prior identification of a specific portfolio of variables (input data for forecasting models) which are explanatory of the phenomenon to be foreseen and therefore significantly influence the pricing (output for forecasting models). The forecasting models, in fact, will learn the characteristics of the phenomenon to be foreseen by the variables of input selected and by historical data that represent the phenomenon analyzed. Models predicting the financial phenomena, developed by economic theory over the years, can be classified into two main categories:

- structural prediction models or linear ones, such as econometric models as Autoregressive Conditional Heteroschedasticity (ARCH), Generalized Autoregressive Conditional Heteroschedasticity (GARCH), State Space, which are based on the general view that every action of traders can be explained by a model of behaviour and thus by a definite, explicit function that can bind variables determinants of the phenomenon to be foreseen;

- black box forecasting models or non-linear ones, such as neural networks, genetic algorithms, expert systems or fuzzy models, which, through the learning of the problem analyzed, attempting to identify and predict the non random and non-linear dynamics of prices, but without explicit ties and logical functions that bind the variables analyzed.

This paper will deepen in particular the second class of forecasting models, through the development and empirical application of a neural network model for forecasting the exchange rate EUR/USD for up to three days ahead of last data available.

\section{A Literature Review}

The literature on the application of artificial intelligence systems (such as neural networks, expert systems, fuzzy models and genetic algorithms) to the fields of economics and finance has explored various aspects. In particular lots of studies have analyzed the application of these models on time series forecasting.

Over the years, the literature has produced several studies to highlight both the critical factors and point of strengths of artificial intelligence models in the forecasting of financial phenomena and to propose tools to facilitate trading in financial markets.

Among the most significant contributions we can mention Yu and Bang [58], Zhang, Patuwo and Hu [59], Kashei, Hejazi and Bijari [60], Wong, Xia and Chu [61], Yu and Huarng [62].

In the paper of H. Y. Yu and S. Y. Bang [58], the authors develop a new learning algorithm for the FIR neu- 
ral network model by applying the idea of the optimization layer by layer to the model. The results of the experiment, using two popular time series prediction problems, show that the new algorithm is far better in learning time and more accurate in prediction performance than the original learning algorithm. The FIR neural network model can be proposed for time series prediction giving good results. However, the learning algorithm used for the FIR network is a kind of gradient descent method and hence inherits all the well-known problems of the method.

G. P. Zhang, B. E. Patuwo and M. Y. Hu [59] presents an experimental evaluation of neural networks for nonlinear time-series forecasting. The effects of three main factors (input nodes, hidden nodes and sample size) are examined through a simulated computer experiment. Results show that neural networks are valuable tools for modelling and forecasting nonlinear time series while traditional linear methods are not as competent for this task. The number of input nodes is much more important than the number of hidden nodes in neural network model building for forecasting. Moreover, large sample is helpful to ease the over fitting problem.

In the paper of M. Khashei, S. R. Hejazi and M. Bijari [60], based on the basic concepts of ANNs and fuzzy regression models, a new hybrid method is proposed that yields more accurate results with incomplete data sets. In their proposed model, the advantages of ANNs and fuzzy regression are combined to overcome the limitations in both ANNs and fuzzy regression models. The empirical results of financial market forecasting indicate that the proposed model can be an effective way of improving forecasting accuracy.

In the study of W. K. Wong, M. Xia and W. C. Chu [61], a novel adaptive neural network (ADNN) with the adaptive metrics of inputs and a new mechanism for admixture of outputs is proposed for time-series prediction. The adaptive metrics of inputs can solve the problems of amplitude changing and trend determination, and avoid the over-fitting of networks. The new mechanism for admixture of outputs can adjust forecasting results by the relative error and make them more accurate. The proposed ADNN method can predict periodical time-series with a complicated structure. The experimental results show that the proposed model outperforms the auto-regression (AR), artificial neural network (ANN), and adaptive k-nearest neighbors (AKN) models. The ADNN model is proved to benefit from the merits of the ANN and the AKN through its' novel structure with high robustness particularly for both chaotic and real time-series predictions.

The paper of T. H. K. Yu and K. H. Huarng [62] intends to apply neural networks to implement a new fuzzy time series model to improve forecasting. Differing from previous studies, this study includes the various degrees of membership in establishing fuzzy relationships, which assist in capturing the relationships more properly. These fuzzy relationships are then used to forecast the stock index in Taiwan. This study performs out-of-sample forecasting and the results are compared with those of previous studies to demonstrate the performance of the proposed model.

\section{The Construction of the Data Base}

The construction of the data base used to train the artificial neural network (ANN) developed was divided into the following three phases:

- data collection;

- data analysis;

- variable selection.

The phase of data collection must achieve the following objectives:

- regularity in the frequency of the data collection by the markets;

- homogeneity between the information provided to the ANN and that available for the market operators.

In the phase of the data collection, we were, therefore, initially considered, as variables of input, both macroeconomic variables (fundamental data) and market data, from which it was assumed that the behaviour of the exchange rate euro-dollar was conditional. The data were collected from January 1999 to December 31, 2009 . The variables of input are listed in the Table 1, indicating the frequency of the data collection and the acronyms of variables used in the tables of the similarity matrix.

Once collected all the data, we moved to the stage of their analysis, which aims to select the data that will be used to train ANN among those initially collected. This phase is crucial, because the learning capacity of the ANN depends on the quality of information provided, which is the capacity of this information to provide a true representation of the phenomenon without producing ambiguous, distorting or amplifying effects in the phases of training networks.

In this phase, the observation of the correlation or similarity coefficients (shown below in Tables 2 and 3) allow to evaluate the nature of relations between the variables of input considered, suggesting the elimination of the variables highly correlated with each other and therefore capable to product amplifying or distorting effects during the training phases.

Tables $\mathbf{2}$ and $\mathbf{3}$ show, respectively, the coefficients of

\footnotetext{
${ }^{1}$ Source of data are Bloomberg and Borsa Italiana.
} 
Table 1. Variables of input initially selected.

\begin{tabular}{|c|c|}
\hline Variables & Frequency \\
\hline Dow Jones Euro Stoxx 50 Index & Daily \\
\hline FTSE 100 Index & Daily \\
\hline $\begin{array}{l}\text { National Association of Securities Dealers Automated } \\
\text { Quotation - Nasdaq Composite Index (NASDAQ) }\end{array}$ & Daily \\
\hline Cotation Assistée en Continu - CAC 40 index (CAC) & Daily \\
\hline Deutscher Aktien Index (DAX) & Daily \\
\hline Dow Jones Industrial Average (DOW JONES) & Daily \\
\hline Standard and Poor's 500 Index (SP) & Daily \\
\hline Exchange Rate EUR/GBP (GBP) & Daily \\
\hline Exchange Rate EUR/YEN (YEN) & Daily \\
\hline Exchange Rate EUR/USD (USD) & Daily \\
\hline Exchange Rate EUR/NZD (NZD) & Daily \\
\hline Gold Spot Price USA (GOLDS) & Daily \\
\hline Silver Spot Price USA (SILV) & Daily \\
\hline Oil Price (CLA) & Daily \\
\hline Natural Gas Accounts (NGA) & Daily \\
\hline LIBOR Rate 3m \$ (L3M) & Daily \\
\hline EURIBOR Rate 3M € (EU3M) & Daily \\
\hline $\begin{array}{l}\text { Avarage yield on Government Bond to } 2 \text { years in U.S. } \\
\text { area (usgg2yr) }\end{array}$ & Daily \\
\hline $\begin{array}{l}\text { Avarage yield on Government Bond to } 5 \text { years in U.S. } \\
\text { area (usgg5yr) }\end{array}$ & Daily \\
\hline $\begin{array}{l}\text { Avarage yield on Government Bond to } 5 \text { years in } \\
\text { Eurozone (gecu5yr) }\end{array}$ & Daily \\
\hline $\begin{array}{l}\text { Avarage yield on Government Bond to } 2 \text { years in } \\
\text { Eurozone (gecu2yr) }\end{array}$ & Daily \\
\hline Monetary Aggregate M1 USA \$ (M1\$YOY) & Monthly \\
\hline Monetary Aggregate M2 USA \$ (M2\$YOY) & Monthly \\
\hline Monetary Aggregate M1 Euro € (M1€ YOY) & Monthly \\
\hline Monetary Aggregate M2 Euro $€$ (M2€ YOY) & Monthly \\
\hline Consumer Price Indices Euro a/a (ECCPEMUY) & Monthly \\
\hline Consumer Price Indices USA a/a (CPI YOY) & Monthly \\
\hline Eur Trade Balance (XTSBEZ) & Monthly \\
\hline USA Trade Balance (USTBTOT) & Monthly \\
\hline Eur Consumer Confidence (EUCCEMU) & Monthly \\
\hline USA Consumer Confidence (CONCCONF) & Monthly \\
\hline Eur Investor Confidence (EUBCI) & Monthly \\
\hline Eur Industrial Confidence (EUICEMU) & Monthly \\
\hline Eur Unemployment Rate (UMRTEMU) & Monthly \\
\hline USA Unemployment Rate (USURTOT) & Monthly \\
\hline $\begin{array}{l}\text { Eurostat Eurozone Monthly Production in Construction } \\
\text { SA (EUPREMU) }\end{array}$ & Monthly \\
\hline $\begin{array}{l}\text { USA Index of real estate - Nahb Stati Uniti } \\
\text { (USHBMIDX) }\end{array}$ & Monthly \\
\hline USA Retail Sales (RSTAMOM) & Monthly \\
\hline USA Government Debt (DEBPTOTL) & Monthly \\
\hline Eur Industrial Production (EUIPEMUY) & Monthly \\
\hline USA Industrial Production (IP YOY) & Monthly \\
\hline Deficit/surplus \% Pil USA (FDDSGDP) & Monthly \\
\hline
\end{tabular}

correlation or similarity of the daily and monthly initial variables.

Following the analysis of the correlation coefficients, we moved to the stage of selection of variables and we eliminated the variables with the following characteristics:

- variables characterized by a Pearson correlation coefficient with at least one other variable considered above the threshold level of acceptance equal to $0.80^{2}$;

- monthly variables, because, having developed a neural network with a daily frequency of data collection of variables of input and output, they were considered potentially able to produce ambiguous or redundant signals during the training of ANN.

As a result of the selection of variables conducted according to the criteria outlined above, we have the final set of seven input variables to train the neural network, which is in the next section. In establishing the final data set with data of the seven input variables, exceptional values, as the outliers, were also removed related to special historical events such as the terrorist attacks of September 11, 2001.

\section{The Methodology for the Development of the Artificial Neural Network Model}

The objective of the ANN is to predict the trend of the exchange rate Euro/USD up to three days ahead of last data available. The variable of output of the ANN designed is then the daily exchange rate Euro/Dollar and the frequency of data collection of variables of input and the output is daily.

In drawing up the network it was considered that the exchange rate is characterized by the so-called phenomenon of mean reversion ${ }^{3}$, or by the tendency not to maintain a trend up or down for a long time ${ }^{4}$.

As noted in paragraph 3 , as a result of the processing steps of the data base, we have selected the following seven variables of input of the ANN.

\footnotetext{
${ }^{2}$ Since the coefficient of correlation or similarity between two variables analyzed both at the time " $\mathrm{t}$ " is merely indicate what the change of a variable " $x$ " is similar to the change of a variable " $y$ ", which follow the same trend, it was considered necessary to eliminate the variables most strongly correlated with each other in order to avoid potentially ambiguous or amplifying signals in the stages of training. The fact of considering as input of a neural network two or more variables strongly correlated (i.e. Pearson's coefficient $>0.80$ ), would artificially boost the information provided by the neural network variables in question. ${ }^{3}$ See Gabbi (1999), pag. 241.

${ }^{4}$ Empirical evidence shows that exchange rates tend to remain sufficiently stable in the medium term around a mean value of equilibrium. It occurs that too high values compared with the average period reflect a tendency to return later to the media. The prediction of these variables, therefore, may be affected by distorting effects produced by historical dynamic, as the typical behaviour of the series is precisely to reverse the trend.
} 


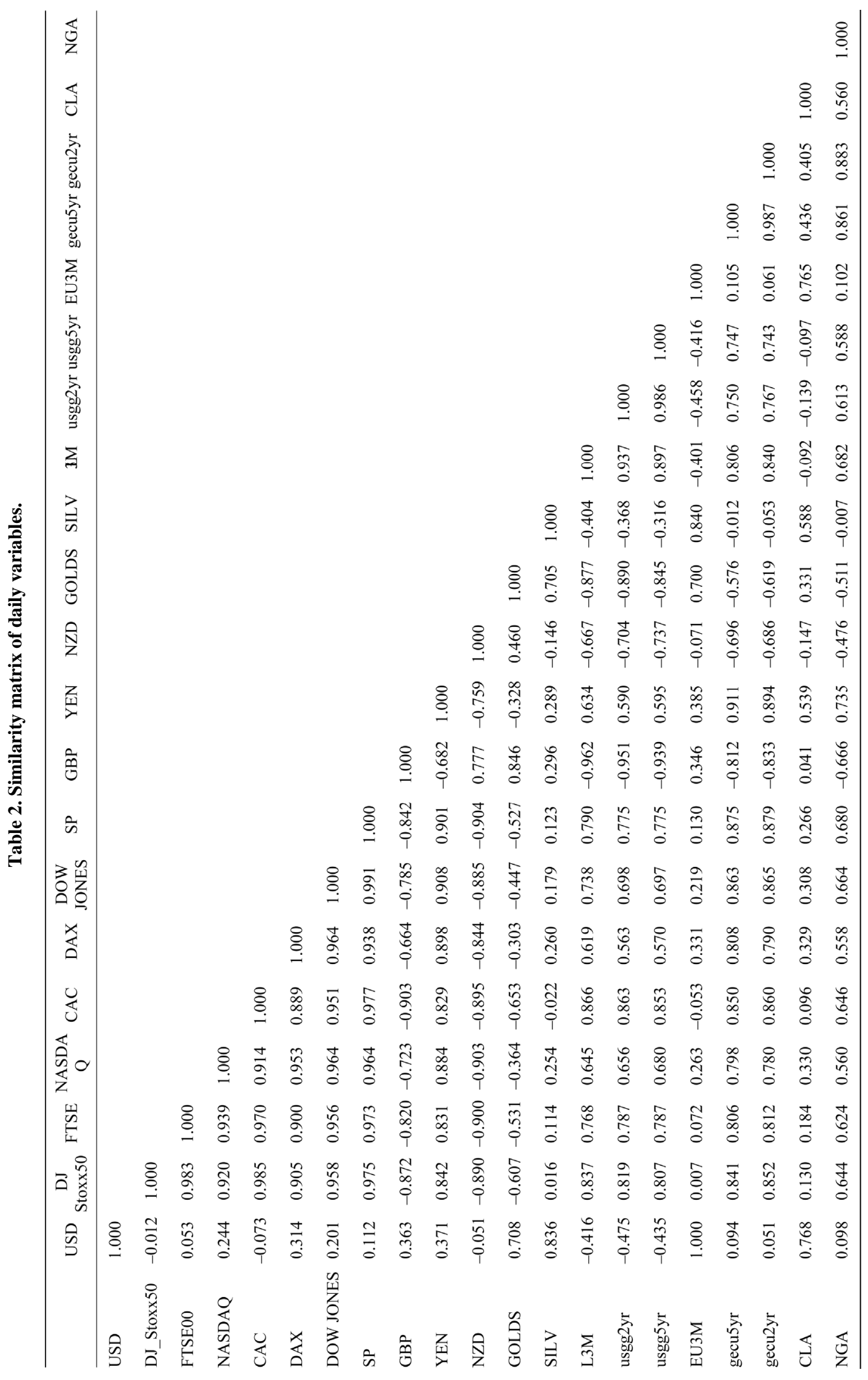




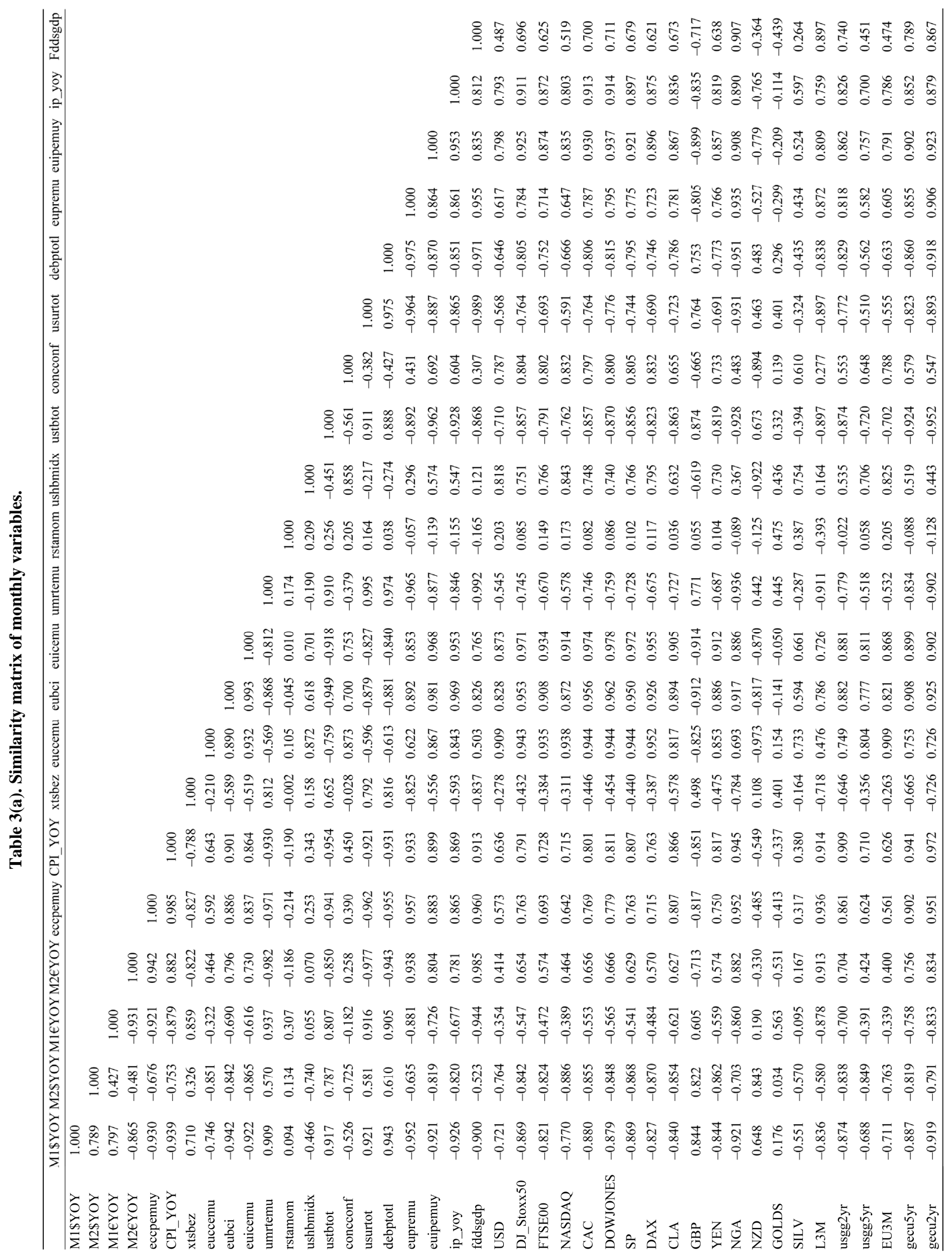




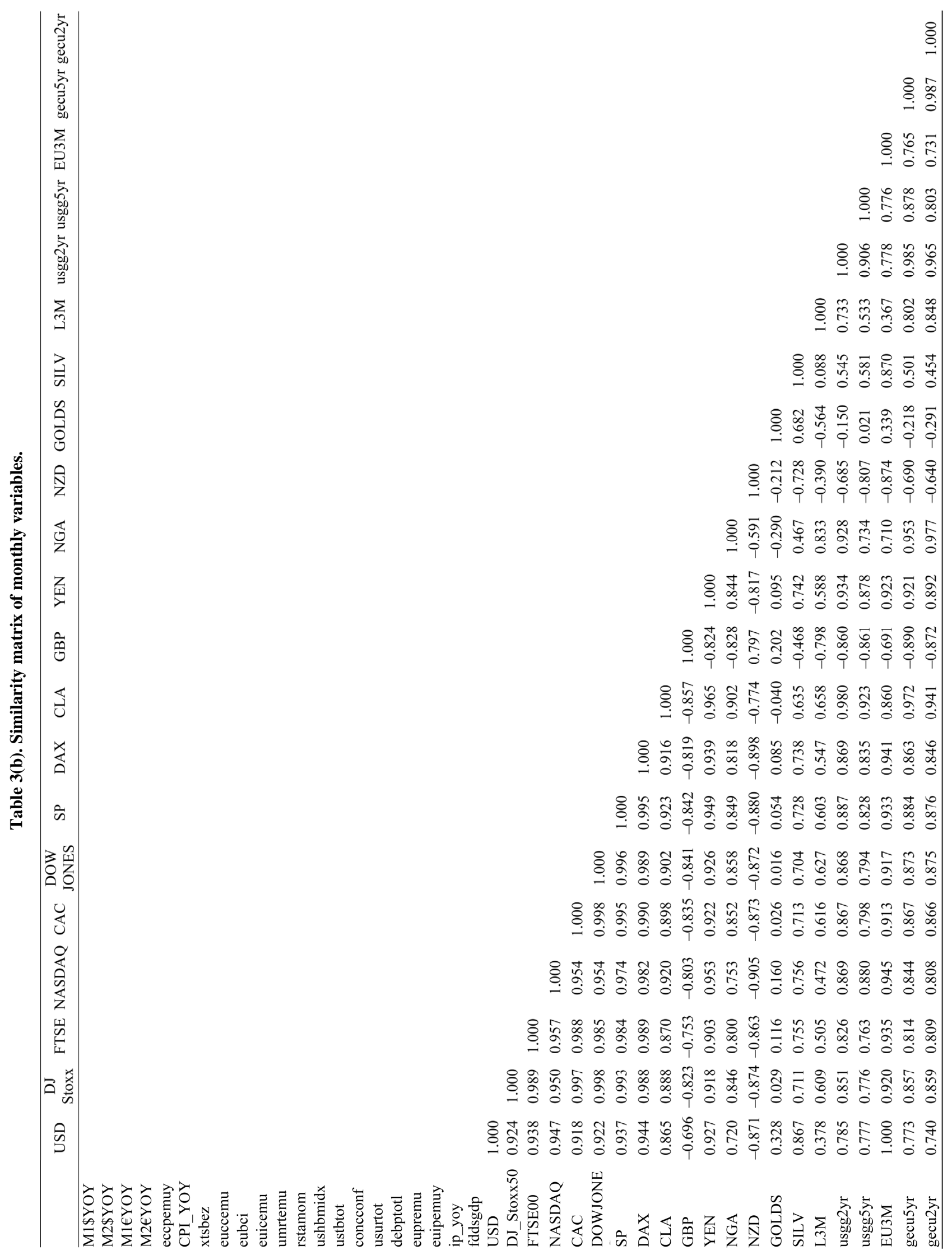


- Nasdaq Index;

- Daily Exchange Rate Eur/USD New Zeland;

- Gold Spot Price USA;

- Average returns of Government Bonds-5 years in the USA zone;

- Average returns of Government Bonds-5 years in the Eurozone;

- Crude Oil Price-CLA (Crude oil);

- Exchange rate Euro/US dollar of the previous day compared to the day of the output.

For each of these variables of input historical memory was calculated, which is the number of daily observations in which it is very high the possibility that the daily value of the variables is self-correlated with the values of $\mathrm{n}$ days ${ }^{5}$.

The historical memory was calculated by an polynomial interpolation with coefficient $\mathrm{R}^{2}$ equal to 0.98 for $90 \%$ of cases. The historical memories calculated for each variable are:

- Nasdaq index: eight surveys;

- Daily exchange rate Euro/NZ Dollar: five surveys;

- Spot price of gold expressed in dollars per ounce: six surveys;

- Average returns of government bonds- 5 years in the USA: eight surveys;

- Average returns of government bonds-5 years in the Eurozone: seven surveys;

- The price of crude oil (CLA): eight surveys;

- Exchange rate Euro/USD: seven surveys more output ${ }^{6}$;

In order to predict the trend of historical memories of individual variables by determining the angular coefficients (m), it was used by the software MatLab the function Polyfit ${ }^{7}$, whereas for the first experiments a degree of the polynomial approximation of $1^{8}$.

Since the ANN uses values between -1 and 1 where it is used the activation function Tansig ${ }^{9}$, it was necessary to normalize data through the interpolation performed with MatLab assigning values between -1 and 1 to vary of the value of the angular coefficient (m) produced by

\footnotetext{
${ }^{5}$ The construction of the data set the neural network is based on the concept of historical memory as the objective of the ANN is to predict the trend of the exchange rate Euro/Dollar.

${ }^{6}$ To train the neural network it is considered as current moment t-2 for each variable, so as to obtain two readings back in order to predict a trend output rate Eur/U.S. dollar equal to three days.

${ }^{7}$ Function polyfit: polyfit $p=(x, f x, n)$. The polyfit is a function used for the construction of polynomial interpolation, where $x$ is the vector that contains the nodes of the grid, $f x$ is the vector containing the values to interpolate on the grid nodes, $n$ is the degree of the polynomial interpolation.

${ }^{8} \mathrm{~A}$ function polyfit degree of approximation equal to 1 (i.e. $n=1$ ) is a polynomial of first degree which interpolates the data as if making a linear regression values.

${ }^{9}$ Hyperbolic tangent sigmoid activation function. Tansig $(n)=2 /(1+$ $\exp (-2 * n))-1$, where $\mathrm{n}$ is the matrix of inputs. The results of a function Tansig can vary between -1 and 1 .
}

the Polyfit, according to the following summary:

$\begin{array}{llll}\text { IF } & 0<=\mathrm{m}<=0.1 & \text { Then } & \text { value }=0.2 \\ \text { IF } & 0.1<\mathrm{m}<=1.1 & \text { Then } & \text { value }=0.4 \\ \text { IF } & 1.1<\mathrm{m}<=3.1 & \text { Then } & \text { value }=0.6 \\ \text { IF } & 3.1<\mathrm{m}<=7.1 & \text { Then } & \text { value }=0.8 \\ \text { IF } & \mathrm{m}>7.1 & \text { Then } & \text { value }=1 \\ \text { IF } & -0.1<=\mathrm{m}<0 & \text { Then } & \text { value }=-0.2 \\ \text { IF } & -1.1<=\mathrm{m}<-0.1 & \text { Then } & \text { value }=-0.4 \\ \text { IF } & -3.1<=\mathrm{m}<-0.1 & \text { Then } & \text { value }=-0.6 \\ \text { IF } & -7.1<=\mathrm{m}<3.1 & \text { Then } & \text { value }=-0.8 \\ \text { IF } & \mathrm{m}<-7.1 & \text { Then } & \text { value }=-1\end{array}$

As shown by the previous scheme, the change of the angular coefficient determines the change in trend growth or reduction of the exchange rate Euro/USD USA.

The inputs of the network were reduced by 49 (i.e. 7 input with their historical memories) to 7 , while the records $^{10}$ are 547.

To optimize the performance of the network we have reduced the data set to avoid signal of distortion or enhancement of some information, using 160 examples of maximum variance, of which 75\% (120 examples) for training set and $25 \%$ (40 samples) for the validation set.

\section{Optimal Topology Design Multi Layer Perceptron Neural (MLP) through a Multi-Objective Genetic Algorithm}

The problem of finding the optimal topology of a Multi Layer Perceptron (MLP) neural network as a trade-off between the performance in terms of precision and the performance in terms of generalization, avoiding the problems of overfitting during the training phase, has been analyzed in the literature very accurately [63] and described in details in terms of an innovative genetic algorithm multi-objective Pareto-Based optimization problems [64] in which a bi-objective functions problems has been formulated and implemented. In fact decisions made in the network designing phase could turn out to be critical and choices non coherent with the problem could influence negatively learning or generalization ability of the Intelligent System. In this field evolutionary techniques have proven to be a great support in exploring the complex spaces that characterize the designing process. The setup of a neural network can be thought of as an optimization problem, indeed. The employment of such techniques appeared to be the optimal method in order to find a competitive solution.

Genetic Algorithms (GAs) are well established bioinspired computational optimization approaches with a wide range of applications that spans from finance to medicine, inspired by the evolutionist theory explaining the origin of species. Following what happens in nature,

\footnotetext{
${ }^{10} \mathrm{~A}$ record is a set of values of input variables and output.
} 
weak species within their environment are faced with extinction by natural selection. The strong ones have greater opportunity to pass their genes to future generations via reproduction. If these changes provide additional advantages in the challenge for survival, new species evolve from the old ones. Unsuccessful changes are eliminated by natural selection. In GA terminology, a solution vector $X$ is called an individual or a chromosome. Chromosomes are made of discrete units called genes. Each gene controls one or more features of the chromosome. In the original implementation of GA by Holland, genes are assumed to be binary digits. In later implementations, more varied gene types have been introduced. Normally, a chromosome corresponds to a unique solution $X$ in the solution space. This requires a mapping mechanism between the solution space and the chromosomes. Being a population-based approach, GA are well suited to solve multi-objective optimization problems. A generic single-objective GA can be modified to find a set of multiple non-dominated solutions in a single run. The ability of GA to simultaneously search different regions of a solution space makes it possible to find a different set of solutions for difficult problems with non-convex, discontinuous, and multi-modal solutions spaces. In particular, Multi-Objective Genetic Algorithms are an extension of GAs and show their best performance when other common methods to simultaneously consider multiple objectives combining them linearly with fixed weights fail. In non MOGA strategy a linear combinations actually transform multiple objectives into a single objective, unfortunately such combinations cause the loss of diversity in potential solutions and then to overcome this shortcoming, Pareto optimal solutions are applied to retain the diversity.

\section{Definition: Pareto Optimal Solutions}

Let $x_{0}, x_{1}, x_{2} \in F$, and $F$ is a feasible region. And $x_{0}$ is called the Pareto optimal solution in the minimization problem if the following conditions are satisfied.

- If $f\left(x_{1}\right)$ is said to be partially greater than $f\left(x_{2}\right)$, i.e. $f_{i}\left(x_{1}\right) \geq f_{i}\left(x_{2}\right), \forall i=1,2, \cdots, n$ and $f_{i}\left(x_{1}\right)>f_{i}\left(x_{2}\right), \exists i=1,2, \cdots, n$, Then $x_{1}$ is said to be dominated by $x_{2}$.

- If there is no $x \in F \quad$ s.t. $x$ dominates $x_{0}$, then $x_{0}$ is the Pareto optimal solutions.

The geometric interpretation of Pareto optimal solutions for a bi-objective problem is demonstrated in Figure 1.

Then the definition of Pareto optimal solution is applied to determine which solutions in the set are Pareto optimal. The step repeats in every generation in MOGA.

The complete MOGA algorithm is introduced in Figure 2 and the details of each step are explained in the following.

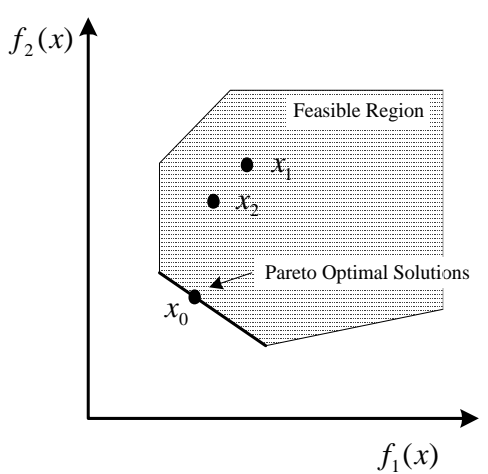

Figure 1. Pareto optimal solutions in the bi-objective problem.

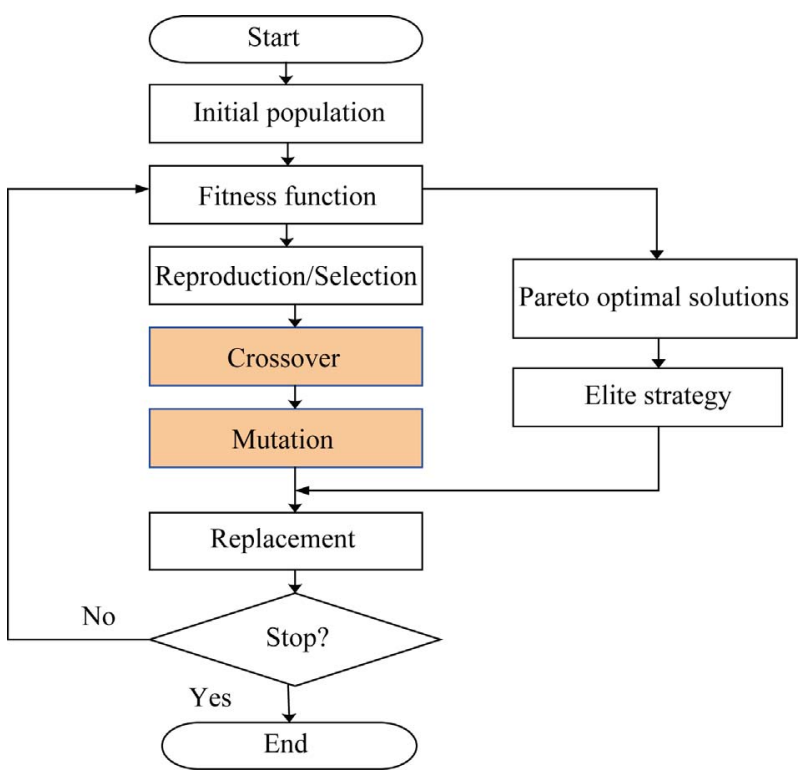

Figure 2. Steps of MOGA.

Moreover, it is well known that $90 \%$ of the approaches to multi-objective optimization aimed to approximate the true Pareto front for the underlying problem. A majority of these used a meta-heuristic technique, and $70 \%$ of all meta-heuristics approaches were based on evolutionary approaches. From this perspective it could be easily intended how MOGAs can be used in order to carry out a MLP topology optimization. In this paper each MLP neural topology developed for this research was trained on data sets described in paragraph 3 by monitoring two parameters of precision and generalization, which can be considered indicators of network quality, capacity or indices of the same set of learning of training data and generalize a set of separate data, not participating in the training phase. Generalization and accuracy were calculated as mean square error over all 120 training examples and all 40 examples of validation considered. In particular, for the purposes of this research, the optimal MLP 
neural network topology has been designed and tested by means the specific genetic algorithm multi-objective Pareto-Based designed from Bevilacqua et al. [64], taking into account the following parameters:

- number of neurons for layer;

- number of layers;

- activation functions of all neurons per each layer; value of the learning rate.

The proposed solution proved to be able to reach a good level of optimization in terms of generalization performance and showed to be able to prune several original architectures designed formerly.

\section{Analysis of the Results}

In Table 4 below it is summarized the characteristics and performance of the three best ANN designed for the purpose of this research which have provided, at the same performance of the training set of $100 \%$, the best results for validation sets, respectively $70 \%, 60 \%$ and $80 \%$.

The first two ANN are designed with the construction technique trial and error and the third network with optimized construction technique mentioned above in paragraph 5.

The third topology neural network designed with an optimized construction technique gives the best performance since it classifies correctly 120 examples of

Table 4. Characteristics and performance of the three best topologies of neural networks designed.

\begin{tabular}{|c|c|c|c|c|}
\hline \multicolumn{5}{|c|}{$\begin{array}{l}\text { First ANN Topology with Technology Building designed trial and } \\
\text { error }\end{array}$} \\
\hline $\mathrm{N}^{\circ}$ inputs & First Layer & Second Layer & $\mathrm{N}^{\circ}$ output & Performance \\
\hline 7 & 11 & 8 & 1 & $\begin{array}{c}120 / 120 \\
28 / 40\end{array}$ \\
\hline $\begin{array}{l}\text { Activation } \\
\text { Function }\end{array}$ & Tansig & Tansig & Tansig & \\
\hline
\end{tabular}

Second ANN Topology with Technology Building designed trial and error

\begin{tabular}{ccccc}
\hline $\mathrm{N}^{\circ}$ inputs & First Layer & Second Layer & $\mathrm{N}^{\circ}$ output & Performance \\
7 & 12 & 9 & 1 & $120 / 120$ \\
& & & & $24 / 40$ \\
$\begin{array}{c}\text { Activation } \\
\text { Function }\end{array}$ & Tansig & Tansig & Tansig & \\
\hline
\end{tabular}

Third and optimal ANN Topology designed with optimized construction technique

\begin{tabular}{ccccc}
\hline $\mathrm{N}^{\circ}$ inputs & First Layer & Second Layer & $\mathrm{N}^{\circ}$ output & Performance \\
7 & 12 & 9 & 1 & $120 / 120$ \\
& & & & $32 / 40$ \\
$\begin{array}{c}\text { Activation } \\
\text { Function }\end{array}$ & Tansig & Tansig & Tansig & \\
\hline
\end{tabular}

120 in the training phase (performance of $100 \%$ ) and 32 examples of 40 during validation (performance of $80 \%$ ) using as classification decreasing range $[-0.2 ;-0.04]$ and as a growing range of classification $[0.04 ; 0.2]$. The bandwidth of the network indecision is then amplitude namely 0.08 [-0.04; +0.04$]$.

Table 5 shows some indicators of statistical error that can provide useful information on good predictive power of the third neural network topology designed with optimized design and manufacturing. By the analysis of the data it is possible to say that the ANN model developed can largely predict the trend to three days of exchange rate Euro/USD.

\section{Conclusions}

By the empirical results it is possible to say, first of all, that empirical research conducted largely support the two research hypothesis discussed in section 1 , justifying the attempt to forecast the exchange rate Euro/USD performed in this research through a non-linear methodology. The good forecasting performance of the network developed show that the process of formation of rate exchange is not completely governed by noise.

The research therefore provides evidence to support the hypothesis of serial dependence of prices in financial markets, according to which prices evolve according to a trend not completely random, and then, at least in part, predictable. This hypothesis, which draws its origins from chaos theory applied to financial systems [46,6572], is based on the idea that what the theory of random walk considers noise, it is probably the result of complex interaction between different market players, who react to the dynamics of price with behaviours that can be better identified by models of nonlinear nature. Therefore, the analysis provides evidence to support the research hypothesis that the processes of pricing in financial markets have seemingly ruled by chance but in reality are determined by interaction between actors and relationships between variables of nonlinear nature, which are difficult to detect because of the chaotic component that

Table 5. Statistical indicators of performance of the best ANN topology designed with optimized design.

\begin{tabular}{ll}
\hline Coefficient & Result \\
\hline Coefficient of determination R ${ }^{2}$ & 0.946 \\
MAE (Mean Absolute Error) & 0.0835 \\
MSE (Mean Square Error) & 0.0316 \\
MSEP (Mean Square Percentage Error) & 0.7911 \\
RMSE (Root Mean Square Error) & 0.1779 \\
RMSEP (Root Mean Square Percentage Error) & 0.8895 \\
\hline
\end{tabular}


characterizes the process of pricing in financial markets, the non-exhaustive information available to build effective predictive models and the inadequacy of many forecasting models. The considerations highlighted above lead to a final consideration [73], which is essentially methodological and is about the effectiveness of an integrated approach, which is based on the joint use of linear and non-linear methods of analysis to study the phenomenon of the forecasting of financial prices.

\section{Acknowledgements}

The authors acknowledge to the anonymous referees for their thoughtful and constructive suggestions and Maria Rosaria Di Muro for the valuable support.

\section{REFERENCES}

[1] G. Cassel, "Money and Foreign Exchange 1914,” Macmillan, New York, 1923.

[2] P. A. Samuelson, "Theoretical Notes on Trade Problems," Review of Economics and Statistics, Vol. 46, No. 2, 1964, pp. 145-154. doi:10.2307/1928178

[3] J. A. Frankel, "Zen and the Art of Modem Macroeconomics: A Commentary,” In: W. S. Harafat, T. D. Willet, Eds., Monetary Policy for a Volatile Global Economy, American Enterprise Institute for Public Policy Research, Washington DC, 1990, pp. 117-123.

[4] R. MacDonald, "Exchange Rate Behavior: Are Fundamentals Important?” The Economic Journal, Vol. 109, No. 459, 1999, pp. 673-691. doi:10.1111/1468-0297.00479

[5] J. D. Alba and D. H. Papell, "Purchasing Power Parity and Country Characteristics: Evidence from Panel Data Tests,” Journal of Development Economics, Vol. 83, No. 1, May 2007, pp. 240-251.

doi:10.1016/j.jdeveco.2005.09.006

[6] J. D. Alba and D. Park, "Purchasing Power Parity in Developing Countries: Multi-Period Evidence under the Current Float," World Development, Vol. 31, No. 12, December 2003, pp. 2049-2060. doi:10.1016/j.worlddev.2003.06.008

[7] J. Coakley, R. P. Flood, A. M. Fuertes and M. P. Taylor, "Purchasing Power Parity and the Theory of General Relativity: The First Tests,” Journal of International Money and Finance, Vol. 24, No. 2, March 2005, pp. 293-316. doi:10.1016/j.jimonfin.2004.12.008

[8] B. H. Kim, H. K. Kim and K. Y. Oh, "The Purchasing Power Parity of Southeast Asian Currencies: A TimeVarying Coefficient Approach,” Economic Modelling, Vol. 26, No. 1, January 2009, pp. 96-106. doi:10.1016/j.econmod.2008.05.009

[9] M. Taylor, "Purchasing Power Parity and Real Exchange Rates,” Routledge, London, 2009.

[10] A. Grossmann, M. W. Simpson and C. J. Brown, "The Impact of Deviation from Relative Purchasing Power Parity Equilibrium on U.S. Foreign Direct Investment," The
Quarterly Review of Economics and Finance, Vol. 49, No. 2, May 2009, pp. 521-550.

doi:10.1016/j.qref.2008.02.001

[11] R. Mundell, “International Economics,” MacMillan, New York, 1968

[12] R. Dornbush, "Currency Depreciation, Hoarding and Relative Prices,” Journal of Political Economy, Vol. 81, No. 4, 1973, pp. 893-915. doi:10.1086/260087

[13] R. Dornbush, "Monetary Policy under Exchange Rate Flexibility," Managed Exchange Rate Flexibility: The Recent Experience, Conference Series, Federal Reserve Bank of Boston, Boston, Vol. 20, 1979, pp. 90-122.

[14] F. A. Frenkel, "A Monetary Approach to the Exchange Rate: Doctrinal Aspects and Empirical Evidence,” Scandinavian Journal of Economics, Vol. 78, No. 2, 1976, pp. 200-224. doi:10.2307/3439924

[15] J. A. Frenkel and M. L. Mussa, "Asset Markets, Exchange Rates, and the Balance of Payments," In: W. R. Jones, P. B. Kenen, Eds., Handbook of International Economics, Vol. 2, North-Holland Publishing, Amsterdam, 1985.

[16] K. Rogoff, "Monetary Models of Dollar/Yen/Euro Nominal Exchange Rates: Dead or Undead?” The Economic Journal, Vol. 109, No. 459, 1999, pp. 655-659. doi:10.1111/1468-0297.00477

[17] W. H. Branson, "Stocks and Flows in International Monetary Analysis,” In: A. Ando, R. Herring, R. Martson, Eds., International Aspect of Stabilizations Policies, Federal Reserve Bank of Boston, Boston, 1975.

[18] W. H. Branson and D. W. Henderson, "The Specification and Influence of Asset Markets,” In: W. R. Jones, P. B. Kennen, Eds., Handbook of International Economics, Vol. 2, North-Holland Publications, Amsterdam, 1985.

[19] P. R. Allen and P. B. Kenen, "Asset Markets, Exchange Rates, and Economic Integration,” Cambridge University Press, London, 1980. doi:10.1017/CBO9780511664540

[20] G. Cifarelli and G. Paladino, "Volatility Spillovers and the Role of leading Financial Centres," Quarterly Review, Vol. 53, 2001, pp. 37-71.

[21] J. A. Frankel, "International Capital Mobility and Crowding out in the U.S. Economy: Imperfect Integration of Financial Markets or Goods Markets?” In: R. W. Hafer, Ed., How Open is the U.S Economy? Lexington Books, Lexington, 1986, pp. 33-67.

[22] K. Froot and K. Rogoff, "Perspective on PPP and LongRun Real Exchange Rates,” In: A. Grossman, K. Rogoff, Eds., Handbook of International Economics, North-Holland Publishing, Amsterdam Science, Amsterdam, 1995.

[23] J. A. Frankel, "Monetary and Portfolio Balance Models of the Determination of Exchange Rates,” In: J. A. Frankel, Ed., On Exchange Rates, MIT Press, Cambridge, 1993, pp. 95-116.

[24] W. H. Branson, H. Haltunnen and P. Mason, "Exchange Rates in the Short-Run: The Dollar-Deutsche Mark Rate," European Economic Review, Vol. 10, No. 3, 1977, pp. 303- 
324. doi:10.1016/S0014-2921(77)80002-0

[25] J. A. Frenkel, "Tests of Monetary and Portfolio Balance Models of Exchange Rate Determination,” In: J. F. O. Bilson, R. C. Marston, Eds., Exchange Rate Theory and Practise, University of Chicago Press, Chicago, 1984.

[26] R. Meese and K. Rogoff, "Empirical Exchange Rate Models of the Seventies: How Well Do They Fit out of Sample?” Journal of International Economics, Vol. 14, No. 1-2, 1983, pp. 3-24. doi:10.1016/0022-1996(83)90017-X

[27] D. A. Hsieh, "Testing for Nonlinear Dependence in Daily Foreign Exchange Rates,” Journal of Business, Vol. 62, No. 3, 1989, pp. 329-368.

[28] J. C. Vasillicos, A. Demos and F. Tata, "No Evidence of Chaos but Some Evidence of Multifractals in the Foreign Exchange and Stock Markets,” In: A. J. Crilly, R. A. Earnshaw, H. Jomes, Eds., Application of Fractals and Chaos, Springer-Verlag, Berlin, 1992, pp. 249-265.

[29] F. Leroy and C. Nottola, "Searching for Relevant Fuzzy Patterns in Financial Time Series with Genetic Algorithms with Application to USD/FF Exchange Rates,” Working Paper, 1993.

[30] A. P. Refenes, K. Azema-Barac, L. Chen and S. A. Karoussos, "Currency Exchange Rate Prediction and Neural Network Design Strategies,” Neural Computing \& Applications, Vol. 1, No. 1, 1993, pp. 46-58. doi:10.1007/BF01411374

[31] I. Nabney, C. Dunis, R. Dallaway, S. Leong and W. Redshaw, "Leading Edge Forecasting Techniques for Exchange Rate Prediction,” Financial Economics, Working Papers, Chemical Bank, London, No. 3, 1994.

[32] I. Nabney, C. Dunis, R. Dallaway, S. Leong and W. Redshaw, "Leading Edge Forecasting Techniques for Exchange Rate Prediction,” In: C. Dunis, Ed., Forecasting Financial Markets: Exchange Rates, Interest Rates and Asset Management, John Wiley \& Sons, Chichester, 1996, pp. 227-244.

[33] C. Brooks, "Testing for Nonlinearity in Daily Pound Exchange Rates," Applied Financial Economics, Vol. 6, No. 4, 1996, pp. 307-317. doi:10.1080/096031096334105

[34] P. Tenti, "Forecasting Foreign Exchange Rates Using Recurrent Neural Networks,” Applied Artificial Intelligence, Vol. 10, 1996, pp. 567-581. doi:10.1080/088395196118434

[35] D. R. Dersch, B. G. Flower and S. J. Pickard, "Exchange Rate Trading Using a Fast Retraining Procedure for Generalised Radial Basis Function Networks," Proceedings of 3rd International Conference on Neural Networks in the Capital Markets, London, 11-13 October 1997.

[36] S. Lawrence, C. L. Giles and A. C. Tsoi, "Symbolic Conversion, Grammatical Inference and Rule Extraction for Foreign Exchange Rate Prediction,” In: A. S. Weigend, Y. Abu-Mustafa, A. P. N. Refens, Eds., Decision Technologies for Financial Engineering, World Scientific, Singapore, 1997.

[37] F. A. Rauscher, "Multi Task in a Neural VEC Approach for Exchange Rate Forecasting," Proceedings of 3rd In- ternational Conference on Neural Networks in the Capital Markets, London, 11-13 October 1997.

[38] M. R. El Shazly and H. E. El Shazly, "Comparing the Forecasting Performance of Neural Networks and Forward Exchange Rates,” Journal of Multinational Financial Management, Vol. 7, No. 4, 1997, pp. 345-356. doi:10.1016/S1042-444X(97)00018-2

[39] G. Gabbi, "La Previsione Nei Mercati Finanziari: Trading System, Modelli Econometrici e Reti Neurali,” Bancaria Editrice, Roma, 1999.

[40] R. Gencay, "Linear, Non-Linear and Essential Foreign Exchange Rate Prediction with Simple Technical Trading Rules,” Journal of International Economics, Vol. 47, No. 1, 1999, pp. 91-107. doi:10.1016/S0022-1996(98)00017-8

[41] A. S. Soofi and L. Cao, "Nonlinear Deterministic Forecasting of Daily Peseta-Dollar Exchange Rate,” Economic Letters, Vol. 62, No. 2, 1999, pp. 175-180. doi:10.1016/S0165-1765(98)00134-7

[42] L. Sarno, "Nonlinear Exchange Rate Models: A Selective Overview,” IMF Working Paper, International Monetary Fund Publications, Washington DC, 2003.

[43] M. Alvarez-Dıaz and A. Alvarez, "Forecasting Exchange Rates Using Genetic Algorithms," Applied Economics Letters, Vol. 10, No. 6, 2003, pp. 319-322.

[44] M. Alvarez-Diaz and A. Alvarez, "Genetic Multimodel Composite Forecast for Non-Linear Forecasting of Exchange Rates,” Empirical Economics, Vol. 30, No. 3, 2005, pp. 643-663.

[45] M. Alvarez-Diaz and A. Alvarez, "Forecasting Exchange Rates Using an Evolutionary Neural Network," Applied Financial Economics Letters, Vol. 3, No. 1, 2007, pp. 5-9.

[46] M. Alvarez-Diaz, "Exchange Rates Forecasting: Local or Global Method?” Applied Financial Economics Letters, Vol. 40, No. 15, 2008, pp. 1969-1984.

[47] S. Reitz and M. Taylor, "The Coordination Channel of Foreign Exchange Intervention: A Nonlinear Microstructural Analysis,” European Economic Review, Vol. 52, No. 1, January 2008, pp. 55-76. doi:10.1016/j.euroecorev.2007.06.023

[48] L. Anastakis and N. Mort, "Exchange Rate Forecasting Using a Combined Parametric and Nonparametric SelfOrganising Modelling Approach,” Expert Systems with Applications, Vol. 36, No. 10, December 2009, pp. 1200112011. doi:10.1016/j.eswa.2009.03.057

[49] R. Majhi, G. Panda and G. Sahoo, "Efficient Prediction of Exchange Rates with Low Complexity Artificial Neural Network Models," Expert Systems with Applications, Vol. 36, No. 1, January 2009, pp. 181-189. doi:10.1016/j.eswa.2007.09.005

[50] S. Bereau, A. Lopez-Villavicencio and V. Mignon, “NonLinear Adjustment of the Real Exchange Rate towards Its Equilibrium Value: A Panel Smooth Transition Error Correction Modelling," Economic Modelling, Vol. 27, No. 1, January 2010, pp. 404-416. doi:10.1016/j.econmod.2009.10.007 
[51] S. Norman, "How Well Does Nonlinear Mean Reversion Solve the PPP Puzzle?” Journal of International Money and Finance, Vol. 29, No. 5, 2010, pp. 919-937. doi:10.1016/j.jimonfin.2010.01.009

[52] M. Bildirici, E. A. Alp and O. Ersin, "TAR-Cointegration Neural Network Model: An Empirical Analysis of Exchange Rates and Stock Returns,” Expert Systems with Applications, Vol. 37, No. 1, January 2010, pp. 2-11. doi:10.1016/j.eswa.2009.07.077

[53] J. M. Keynes, “The General Theory of Employment, Interest and Money,” Palgrave MacMillano, London, 1936.

[54] R. J. Schiller, “Stock Price and Social Dynamics,” Brooking Papers on Economic Activity, Vol. 1984, No. 2, 1984, pp. 457-510.

[55] G. Soros, "The Academy of Finance. Reading the Mind of the Market," John Wiley \& Sons, Inc., New York, 1994.

[56] M. Obstfeld and K. Rogoff, "The Six Major Puzzles in International Macroeconomics: Is there a Common Cause?” In: B. Bernanke, K. Rogoff, Eds., NBER Macroeconomics Annual, MIT Press, Cambridge, 2000.

[57] K. Rogoff, "The Failure of Empirical Exchange Rate Models: No Longer New, but Still True,” Web Essay, Economic Policy, 2002. http://www.economic-policy.org/commentaries.asp

[58] H. Y. Yu and S. Y. Bang, “An Improved Time Series Prediction by Applying the Layer-by-Layer Learning Method to FIR Neural Networks," Neural Networks, Vol. 10, No. 9, December 1997, pp. 1717-1729. doi:10.1016/S0893-6080(97)00066-X

[59] G. Zhang, B. E. Patuwo and M. Y. Hu, "Forecasting with Artificial Neural Networks: The State of the Art," International Journal of Forecasting, Vol. 14, No. 1, 1998, pp. 35-62. doi:10.1016/S0169-2070(97)00044-7

[60] M. Khashei, S. R. Hejazi and M. Bijari, “A New Hybrid Artificial Neural Networks and Fuzzy Regression Model for Time Series Forecasting," Fuzzy Sets and Systems, Vol. 159, No. 7, April 2008, pp. 769-786. doi:10.1016/j.fss.2007.10.011

[61] W. K. Wong, M. Xia and W. C. Chu, “Adaptive Neural Network Model for Time-Series Forecasting,” European Journal of Operational Research, Vol. 207, No. 2, December 2010, pp. 807-816.

[62] T. H.-K. Yu and K.-H. Huarng, "A Neural Network-Based Fuzzy Time Series Model to Improve Forecasting,” $E x$ pert Systems with Applications, Vol. 37, No. 4, April
2010, pp. 3366-3372. doi:10.1016/j.eswa.2009.10.013

[63] T. Binos, "Evolving Neural Network Architecture and Weights Using an Evolutionary Algorithm,” Master's Thesis, Department of Computer Science, RMIT University, Melbourne, April 2003, pp. 1-53.

[64] V. Bevilacqua, G. Mastronardi, F. Menolascina, P. Pannarale and A. Pedone, "A Novel Multi-Objective Genetic Algorithm Approach to Artificial Neural Network Topology Optimisation: The Breast Cancer Classification Problem," Proceedings of IEEE International Joint Conference on Neural Networks, Vancouver, 16-21 July 2006, pp. 1958-1965.

[65] D. A. Hsieh, "Chaos and Nonlinear Dynamics: Applications to Financial Markets," Journal of Finance, Vol. 46, No. 5, 1991, pp. 1839-1877. doi:10.2307/2328575

[66] M. Larrain, “Testing Chaos and Nonlinearities in T-Bill Rates,” Financial Analysts Journal, Vol. 47, No. 5, 1991, pp. 51-62. doi:10.2469/faj.v47.n5.51

[67] E. E. Peters, "Chaos and Order in the Capital Markets," John Wiley \& Sons, New York, 1991.

[68] M. D. Weiss, "Nonlinear and Chaotic Dynamics: An Economist's Guide,” Journal of Agricultural Economics Research, Vol. 43, No. 3, 1991, pp. 2-17.

[69] O. Bajo-Rubio, F. Fernandez-Rodriguez and S. SosvillaRovero, "Chaotic Behaviour in Exchange-Rate Series: First Results for the Peseta-U.S. Dollar Case," Economics Letters, Vol. 39, No. 2, 1992, pp. 207-211. doi:10.1016/0165-1765(92)90291-6

[70] R. R. Trippi, "Chaos \& Nonlinear Dynamics in the Financial Markets,” Irwin Professional Publishing, Chicago, 1995.

[71] A. H. W. Low and J. Muthuswamy, "Information Flows in High Frequency Exchange Rates,” In: C. Dunis, Ed., Forecasting Financial Markets. Exchange Rates and Asset Management, John Wiley \& Sons, Chichester, 1996.

[72] U. Anders, T. H. Hann and G. Nakaheizadeh, "Testing for Nonlinearity with Neural Networks,” In: A. S. Weigend, Y. Abu-Mustafa, A. P. N. Refens, Eds., Decision Technologies for Financial Engineering, World Scientific, Singapore, 1997.

[73] V. Pacelli, “An Intelligent Computing Algorithm to Analyze Bank Stock Returns,” Huang et al., Eds., Emerging Intelligent Computing Technology and Applications, Lectures Notes on Computer Sciences, No. 5754, Springer Verlag, New York, 2009. 